\title{
Airway Plateau Pressure
}

National Cancer Institute

\section{Source}

National Cancer Institute. Airway Plateau Pressure. NCI Thesaurus. Code C130051.

The static pressure of the entire respiratory system during inspiratory pause. It reflects the elastic retraction of the entire respiratory system. 